\title{
MHD stagnation point flow of micropolar nanofluid between parallel porous plates with uniform blowing
}

\author{
Mohammad Mehdi Rashidia ${ }^{\mathrm{a}, \mathrm{b}}$, Motahar Reza ${ }^{\mathrm{c}, *}$, Suraj Gupta $^{\mathrm{d}}$, \\ (Revised version)
}

\begin{abstract}
The combine effect of nanoparticle and magnetic field on a micropolar fluid flow between two parallel coaxial porous plates with uniform blowing is investigated in this article. The two kinds of Nanoparticles, i.e. Copper Oxide $(\mathrm{CuO})$ and Alumina $\left(\mathrm{Al}_{2} \mathrm{O}_{3}\right)$ are mixed with base fluid water to prepare the mixture of microplar nanofluid for the analysis of this problem. The convergence analysis of the numerical solutions is considered for large mesh size and high tolerance error. It is interesting to note that the skin friction coefficient at the lower plate increases with increasing the magnetic field for both $\mathrm{CuO}$ - water and $\mathrm{Al}_{2} \mathrm{O}_{3}-$ water micro-polar nanofluid but it decreases with increases in volume fraction of nanoparticles in both the fluids. A novel result is found from this analysis that the rate of heat transfer at the lower plate increases with increasing the either magnetic parameter or micro-rotation parameter or the volume fraction of nanoparticles in the case of both fluids. The effects of magnetic field and micro-rotation parameter on the velocity, micro-rotation, temperature and concentration profiles are analyzed. The radial velocity profiles increase near the stagnation point but decreases near the plates by increasing the blowing parameter.
\end{abstract}

Keywords: $\quad$ Magnetohydrodynamics; Stagnation-point; Micropolar; Nanofluid 


\section{Nomenclature}

$(r, \theta, z)$ polar cylindrical coordinates

\begin{tabular}{|c|c|}
\hline $\mathrm{A}_{1}, \ldots, \mathrm{A}_{5}$ & constants \\
\hline $\mathrm{B}$ & dimensionless microrotation constant \\
\hline B & magnetic field Vector \\
\hline $\mathrm{B}_{0}$ & magnetic flied component \\
\hline$C$ & concentration function \\
\hline$C_{1}$ & concentration of injected fluid through lower plate \\
\hline$C_{2}$ & concentration of injected fluid through upper plate \\
\hline$c_{f}$ & skin friction coefficient \\
\hline $\mathrm{C}_{\mathrm{n}}$ & dimensionless wall couple stress \\
\hline $\mathrm{D}$ & diffusion coefficient \\
\hline $\mathbf{E}$ & electric field \\
\hline Ec & Eckert number \\
\hline $\mathrm{F}$ & dimensionless stream function \\
\hline $\mathrm{G}$ & dimensionless microrotation function \\
\hline g & gravitational acceleration \\
\hline $\mathbf{J}$ & current density \\
\hline $\mathrm{j}$ & micro-inertia \\
\hline $\mathrm{j}_{\mathrm{w}}$ & wall mass flux \\
\hline $\mathrm{k}$ & microrotation parameter \\
\hline $\mathrm{K}_{n f}$ & thermal conductivity \\
\hline $\mathrm{M}$ & Hartman number \\
\hline $\mathrm{m}_{\mathrm{w}}$ & wall couple stress \\
\hline $\mathrm{n}$ & concentration of microelements \\
\hline $\mathrm{Nu}$ & Nusselt Number \\
\hline $\mathrm{p}$ & pressure \\
\hline $\operatorname{Pr}$ & Prandlt number \\
\hline $\mathrm{q}_{\mathrm{w}}$ & wall heat flux \\
\hline $\mathrm{R}$ & dimensionless microrotation parameter \\
\hline $\mathrm{Re}$ & injection Reynolds number \\
\hline $\mathrm{Sc}$ & Schmidt number \\
\hline Sh & Sherwood Number \\
\hline $\mathrm{T}$ & temperature of the fluid inside the boundary layer \\
\hline$T_{1}$ & temperature at the surface of lower plate \\
\hline$T_{2}$ & temperature at the surface of upper plate \\
\hline $\mathbf{u}$ & velocity vector \\
\hline $\mathrm{V}$ & microrotation variable \\
\hline $\mathrm{V}$ & uniform blowing velocity \\
\hline$V r$ & radial velocity component \\
\hline$V z$ & axial velocity component \\
\hline$V \theta$ & azimuth velocity component \\
\hline $\mathbf{w}$ & microrotation vector \\
\hline
\end{tabular}




\section{Greek symbols}

$\begin{array}{ll}(\rho) f & \text { density of the base fluid }\left(\mathrm{kg} / \mathrm{m}^{3}\right) \\ (\rho) n f & \text { effective density of the nanofluid }\left(\mathrm{kg} / \mathrm{m}^{3}\right) \\ (\rho) p & \text { density of a nanoparticle } \\ & \text { effective heat capacity of the nanofluid } \\ & \text { heat capacity of a nanoparticle } \\ & \text { spin gradient viscosity } \\ & \text { effective viscosity (Pa s) } \\ & \text { effective electrical conductivity of the nanofluid } \\ \tau w & \text { the skin friction } \\ \mu_{m} & \text { magnetic permeability } \\ \eta & \text { dimensionless similarity variable } \\ \theta & \text { dimensionless temperature function } \\ \psi & \text { dimensionless concentration function }\end{array}$

\section{Subscripts}

$\begin{array}{ll}f & \text { the base fluid } \\ n f & \text { nanofluid } \\ \mathrm{p} & \text { nanoparticles } \\ \mathrm{w} & \text { condition at the surface }\end{array}$

\section{Introduction}

Understanding fluid flow behavior and heat transfer intensification has always been a point of major interest both scientifically and industrially. Owing to its major importance in many industrial sectors such as power generation, metallurgical, chemical etc. has led to widespread research and continuing innovations in this field. In lieu of meeting up the cooling and heating rates requirements, fluids with high heat transfer characteristics are in the demand. Nanofluid is one such advanced fluids gaining much interest among the researchers owing to its many practical industrial applications. Unlike other conventional heat transfer fluids such as water, ethylene glycol, and mineral oils, nanofluids have very high thermal conductivity and play a crucial role in meeting up the cooling rate requirements. Nanofluids are the composite suspensions with enhanced properties with heat transfer and mass transfer characteristic which is used for many applications in chemical and metallurgical sectors, hybrid powered engine, engine cooling, thermal management, heat exchangers etc. Nanofluids are advanced fluids made up from the suspension of nanoparticles in the base fluids. Base fluids are generally normal conventional fluids with very low heat transfer coefficients such as water, ethylene glycol, kerosene etc. Inclusion of nano-particles in the base fluids enhances the thermal conductivity and other associated factors drastically to many folds. Some of the nano-particles used are $\mathrm{CuO}, \mathrm{Ag}$, $\mathrm{TiO}_{2}$ and $\mathrm{Al}_{2} \mathrm{O}_{3}$. 
The term nanofluid was introduced by Choi [1] et al in 1995. Over the last few decades, many researchers has studied the behavior of nanofluids and its capability of heat transfer enhancement. The experimental investigation was done by Eastman et al [2] and Masuda et al [3] who showed how the inclusion of a small amount of nanoparticles in the base fluid increased its thermal conductivity drastically. Pak et al [4] and Tiwari et al [5] suggested that the heat transfer enhancement due to inclusion of the nanoparticles significantly depends upon the particle size, volumetric fraction and thermal conductivity of the nanoparticles. Later, a number of researchers presented different mathematical models for effective thermal conductivity and viscosity on the basis of their experimental analysis and theoretical assumptions. Buongiorno [6] observed that the absolute velocity of nanoparticles was basically the resultant of the base fluid velocity and the slip velocity of nanoparticles. This ascends the possibility of inclusion of micropolar theory (Eringen [7]-[8]) in order to explain the distinct behavior of nanofluids from other Newtonian fluids and also the nature and structure of micropolar fluids. To construct a mathematical model of the flow of nanofluids, it is necessary to consider both theories, (i) inclusion of effective viscosity and conductivity in the governing equations and (ii) considering slip mechanism of nanoparticles with the base fluid. Bio-nanofluids $\left(\mathrm{Al}_{2} \mathrm{O}_{3}\right.$-water $)$ flow in circular pipe based on single-phase model and two-phase models was investigated by Anwar Beg et al.[9]. A numerical experiment of two-phase and single phase model for $\mathrm{CuO}-$ water nanofluid flow in wavy channel is done by Rashidi et al [10]. Unsteady MHD flow of nanofluid past a porous stretching plate is analyzed by Abolbashari et al [11] and Freidoonimehr et al [12]. An analytic solution for flow of nanofluid over a chemically responding horizontal surface in porous medium is studied by Rashidi et al [13] using optimal HAM (homotopy analysis method) method. Zargartalebi et al [14] studied the heat transfer for stagnation-point flow of nanofluid across the streching plates. Dinarvand et al [15] analyzed the Brownian motion and thermophoresis effect for the nanofluid flow near a vertical surface. Malvandia et al [16] investigated the effect of radial magnetic field of forced convection of a nanofluid through two homocentric horizontal cylinders. Kumar et al [17]-[20] examined the nature of the Brownian motion of the particles based on the various fractional models.

Garoosi et al [21]-[23] investigated the numerical experiment on heat transfer and momentum of nanofluid in square cavity. Lukaszewicz [24] noted that the micropolar theory can explain many unusual behaviors of Non-Newtonian fluids. Hence, it would be insightful to apply micropolar theory in understanding the nanofluid flows. Many researchers have used micropolar nanofluids to study fluid flow behavior in different geometries such as Hussain et al [25] investigated the flow of micropolar nanofluid over stretching surface. Rehman et al [26] studied the mixed heat transfer in micropolar nanofluid over a vertical slender cylinder. Nadeem et al [27] analyzed the axisymmetric stagnation point flow of a micropolar nanofluid in a moving cylinder. Zaraki et al [28] examined the heat transfer characteristic of natural convection of nanofluids due to different shape and size of nanoparticles. Zargartalebi et al [29] studied the effect of variable thermo-physical properties of stagnation flow of nanofluid over stretching surface. Ghalambaz et al [30] investigated the boundary layer flow of nanofluid on stretching sheet by passively controlling of nanoparticles at the sheet. Noghrehabadadi et al [31] analyzed the combine effect of Brownian motion and magnetic flied on naofluid over starching sheet. Noghrehabadi et al [32] studied the natural convection of nanofluid with variable viscosity and thermal conductivity over a vertical plate embedded in a porous medium. 
Fluid flow between the porous or non-porous discs is of real pragmatic significant aspect in both scientific and industrial applications. This type of flow is found in semiconductor manufacturing process with rotating wafers, computer storage device, design of thrust bearings, crystal growth processes, biomechanics, etc. Over the last few years, a number of theoretical and experimental investigations ([33]-[37]) has been made on fluid flow between porous plates/disks with suction or blowing. Rudraiah and Chandrasekhara [38] investigated the flow of an electrically conducting fluid between two parallel porous disks for large suction Reynolds number in the presence of magnetic field. Rasmussen [39] analyzed the symmetric flow behavior between two parallel porous coaxial disks with uniform suction and blowing. Chapman and Bauer [40] gave the numerical and asymptotic solutions of symmetric laminar flow of viscous fluid between porous plates for large and low Reynolds numbers. Elcrat [41] obtained the exact solution of the viscous fluid flow between two coaxial and permeable disks. Gaur et al [42] considered different permeability to study the velocity and temperature distribution of fluid flow through two porous parallel plates in the presence of suction or injection. Bujurke [43] et al obtained similarity solution of the axisymmetric fluid flow through two coaxial disks where one plate is rotating and the other plate is stationary. Later, they examined the series solution of Navier-Stokes equation for axially-symmetric flow of viscous fluid between porous parallel plates for low Reynolds number using perturbation technique [44].

On the other hand, many researchers investigated the micropolar fluid flow between parallel plates and analyzed its significant for various industrial applications. The steady flow of the micropolar fluid between the two parallel disks with uniform injection was analyzed by Agarwal et al [45] which was the extension work of Chapman and Baurer [40]. Guram and Anwar [46] studied the flow of micropolar fluid through one rotating plates and another stationary disc. They also found the numerical solution of the micropolar fluid through the rotating disc in presence of suction or blowing [47]. The heat transfer of micropolar fluid through two parallel porous plate using finite element method was investigated by Takhar et al [48]. A numerical investigation to study the behavior non-Newtonian lubrication in journal bearing with micropolar fluid in presence of the thermal and the cavitation effects was done by Wang et al [49]. The steady flow of micropolar fluid flow due to the blowing through of porous parallel plates was analyzed by Anwar et al [50]. The steady flow of a micropolar fluid between a porous and a non-porous plate with low Reynolds number was discussed by Ashraf et al [51]. A micropolar fluid flow through porous channel having different permeability walls was analyzed by Ashraf et al [52]. Mixed convection of micropolar fluid in horizontal circular cylinder was examined by Nazar et al [53].

The main aim of the present paper is to investigate the effect of nanoparticles on a microplar fluid flow through parallel plates with blowing in the presence of magnetic fluid. Mixture of the base fluid water with nanoparticles Copper Oxide $\mathrm{CuO}$ or Alumina $\mathrm{Al}_{2} \mathrm{O}_{3}$ have been considered to analyze the mathematical model. Using similarity transformation, the governing equations of the problem are reduced to the system of nonlinear ordinary differential equations. The numerical solutions of these equations are obtained using shooting technique with Runge-Kutta method to investigate the velocity distribution, micro-rotation, temperature distribution which are shown graphically. Thermophysical properties with temperature and volume fraction are studied. The effects of magnetic field, micro-rotation and nanoparticle volumetric fraction on skin friction and heat transfer behaviors at the plate are examined. 


\section{Mathematical formulation}

Let us consider hydromagnetic unsteady viscous flow of an incompressible micropolar nanofluid between two parallel porous discs situated at $\mathrm{z}=\mathrm{L}$ and $\mathrm{z}=-\mathrm{L}$ respectively with origin in between the discs at $z=0$ as shown in Fig 1 . The micropolar nanofluid is injected through both the porous plates continuously with uniform velocity having magnitude $V$ which flows radially towards the middle plane $z=0$ with axial symmetry. A transverse magnetic field $\mathbf{B}$ is applied along z-direction. Let $\left(V_{r}, V_{\theta}, V_{z}\right)$ and $\left(v_{1}, v_{2}, v_{3}\right)$ be components of velocity $\mathbf{u}$ and micro-rotation $\mathbf{w}$ in polar cylindrical coordinate system, respectively. Due to axial symmetry, the velocity and micro-rotation components along radial, azimuth and axial direction and temperature distribution are considered as follows:

$$
\begin{aligned}
& V_{r}=V_{r}(r, z), V_{\theta}=0, V_{z}=V_{z}(r, z), \\
& v_{1}=0, v_{2}=v(r, z), v_{3}=0, \\
& T=T(r, z) .
\end{aligned}
$$

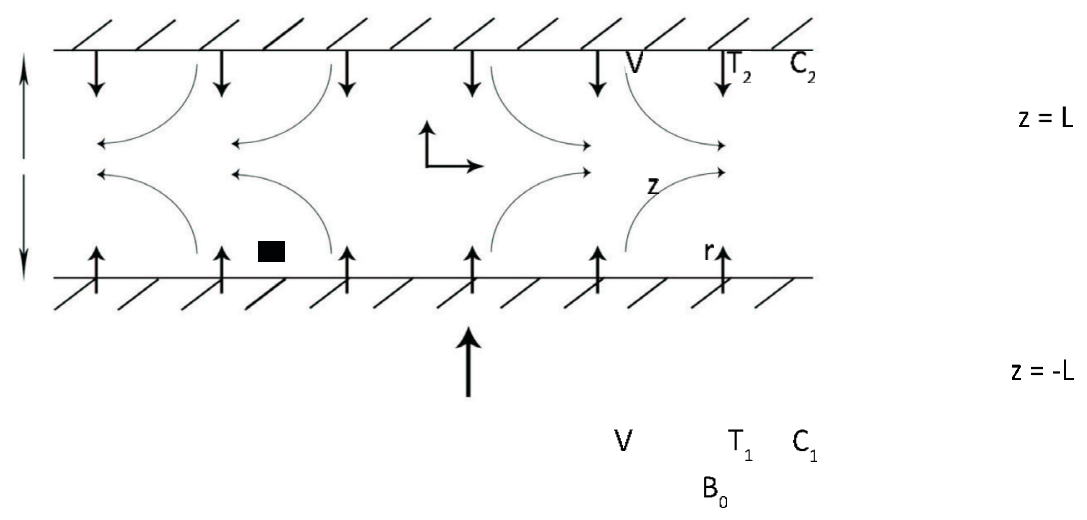

Figure 1: A sketch of the physical problem.

The governing equations of continuity, momentum, energy and concentration distribution for the MHD steady viscous incompressible flow of a micropolar nanofluid are (Eringen [7]-[8]),

$$
\partial V r \partial r+V r r+\partial V z \partial z=0,
$$

$\rho n f V r \partial V r \partial r+V z \partial V r \partial z=-\partial p \partial r-k \partial v \partial r+\mu n f+k \partial 2 V r \partial r 2+1 r \partial V r \partial r+\partial 2 V r \partial z 2-V r r 2-\sigma n f B O$

$2 V r$

$$
\rho n f V r \partial V z \partial r+V z \partial V z \partial z=-\partial p \partial z+k r \partial r v \partial r+\mu n f+k \partial 2 V z \partial r 2+1 r \partial V z \partial r+\partial 2 V z \partial z 2-\rho n f g \text {, }
$$

$\rho n f j V r \partial v \partial r+V z \partial v \partial z=\gamma n f \partial \partial r \partial v \partial r+v r+\partial 2 v \partial z 2+k \partial V r \partial z-\partial V z \partial r-2 k v$,

$$
(\rho C p) n f V z \partial T \partial z=K n f \partial 2 T \partial z 2+\mu n f+k \partial V r \partial z 2+\sigma n f B 02 V r \text {, }
$$




$$
V z \partial C \partial z=D \partial 2 C \partial z 2,
$$

$$
\nabla . \mathbf{B}=0,
$$

$$
\nabla \times \boldsymbol{B}=\mu_{m} \mathbf{J},
$$

$$
\nabla \times \mathbf{E}=0,
$$

$$
\mathbf{J}=\sigma_{e}(\mathbf{E}+\mathbf{u} \times \mathbf{B})
$$

where $\rho_{n f}$ is the effective density, $\mu_{n f}$ is the effective viscosity of the nanofluid, $\gamma_{n f}$ is the spin gradient viscosity depending upon nanofluid dynamic viscosity, $\mathrm{j}$ is the micro-inertia, $K_{n f}$ is the effective thermal conductivity and $\sigma_{n f}$ is the effective electrical conductivity of the nanofluid and $\left(\rho C_{p}\right)_{n f}$ is effective heat capacity of the nanofluid. Here $\mathbf{J}$ is the current density, $\mu_{m}$ is the magnetic permeability. $\mathbf{E}$ is electric field and $\mathbf{B}=\left(0,0, B_{0}\right)$ is applied magnetic field, $\sigma_{e}$ is the electrical conductivity of the nanofluid. The viscous dissipation and joule heating effects have been taken into account to study the temperature distribution. The temperature of the lower plate and upper plates are considered at the constant temperature $T_{1}$ and $T_{2}$, respectively. The micropolar nanofluid fluid containing the solute at concentration $C_{1}$ is injected through lower plates and same fluid with the solute at concentration $C_{2}$ is injected through upper plate with uniform constant velocity $V$ in both cases which flows radially towards the middle plane $z=0$ with axial symmetry.

The boundary conditions for the velocity distribution at the two porous plates are

$$
\begin{array}{ll}
V z=V, & \text { at } z=-L, \\
V z=-V, & \text { at } z=L, \\
V r=0, & \text { at } z=-L, \\
V r=0, & \text { at } z=L .
\end{array}
$$

The appropriate boundary conditions for the micro-rotation at the two porous plates are

$$
\begin{array}{cl}
v=-n\left(\partial V_{r} / \partial z\right), & \text { at } \mathrm{z}=-\mathrm{L}, \\
v=-n\left(\partial V_{r} / \partial z\right), & \text { at } \mathrm{z}=\mathrm{L} .
\end{array}
$$

Table 1: Thermophysical properties of Base fluid and nanoparticles [54]

\begin{tabular}{|l|l|l|l|l|}
\hline & $\rho$ & $\mathrm{C}_{\mathrm{p}}$ & $\mathrm{K}(W m . K)$ & $\sigma(\Omega . m)-1$ \\
\hline
\end{tabular}




\begin{tabular}{|c|c|c|c|c|}
\hline & & $(\mathrm{Jkg} . \mathrm{K})$ & & \\
\hline Pure water & 997.11 & 4179 & 0.613 & 0.05 \\
\hline $\mathrm{Al}_{2} \mathrm{O}_{3}$-water & 3970 & 765 & 25 & $10^{-12}$ \\
\hline $\mathrm{CuO}$-water & 6500 & 540 & 18 & $10^{-10}$ \\
\hline
\end{tabular}

It is interesting to note that the concentration of micropolar fluid is controlled by the value of $n$ in $0 \leq n \leq 1$ [41]. Due to the strong concentration of microelements near the surface, i.e. $n=0$, the micro elements cannot rotate near the surface. On the other side, $n=1$, means for weak concentration of the microelements, the anti-symmetric part of the stress-tensors disappear and it turns to have the turbulence characteristic nature of the flow.

The boundary conditions for the temperature distribution and concentration at the porous plates are

$$
\begin{array}{ll}
T=T 1, & \text { at } z=-L, \\
C=C 1, \quad & \text { at } z=L, \\
C=C 2, & \text { at } z=-L,
\end{array}
$$

The correlations for effective density, effective heat capacity, effective viscosity, effective thermal conductivity, the effective electrical conductivity of nanofluid are as follows [55]:

$$
\begin{array}{r}
\rho_{n f}=(1-\varphi) \rho_{f}+\varphi \rho_{p}, \\
\left(\rho C_{p}\right)_{n f}=(1-\varphi)\left(\rho C_{p}\right)_{f}+\varphi\left(\rho C_{p}\right)_{p}, \\
\mu n f \mu f=1(1-\phi) 2.5, \\
K n f K f=K{ }_{p}+2 K_{f}-2 \varphi\left(K_{f}-K_{p}\right) K+2 K+\varphi(K-K), \\
\sigma n f \sigma f=1+3(\sigma p \sigma f-1) \phi(\sigma p \sigma f+2)-(\sigma p \sigma f-1) \phi,
\end{array}
$$

where $\varphi$ is the volume fraction of nanoparticles in nanofluid. Subscript $\mathrm{nf}, \mathrm{f}$ and $\mathrm{s}$ represents nanofluid, base fluid and nanoparticles respectively. In present work, we have focused our study on two systems: $\mathrm{Al}_{2} \mathrm{O}_{3}$-Water and $\mathrm{CuO}$-water, where Water is the base fluid and $\mathrm{Al}_{2} \mathrm{O}_{3}$ and $\mathrm{CuO}$ are the nanoparticles. The thermophysical properties of base fluid and nanoparticles have been listed in Table 1.

As per assumption of the uniform boundary condition which is set by geometrical properties of the model, we can take Following Chapman [23] and Agarwal [30], we assume 
so that

$$
V_{r}=r f(z)
$$

$$
\partial V z \partial z=-2 f z
$$

and using continuity equation (2), we can write

$$
V z=-20 x f z d z .
$$

This implies that $V_{z}$ is a function of $\mathrm{z}$ only and independent of $\mathrm{r}$. For micro-rotation, we assume

$$
v=f g(z) \text {. }
$$

Setting the non-dimensional quantities, we can get

$$
\begin{gathered}
z=\eta L, \\
F \eta=V z V, \\
f \eta=-V 2 L F^{\prime} \eta, \\
g z=-V 4 L 2 G \eta,
\end{gathered}
$$

Using above transformations and elimination of $p$ from (3), it gives

$$
1+R A 2 F^{\prime \prime \prime}-R e A 1 A 2 F F^{\prime \prime \prime}-M A 5 A 2 F^{\prime \prime}-R 2 A 2 G^{\prime \prime}=0 \text {. }
$$

Similarly, equation (5) becomes

$$
B 1+R 2 A 2 G^{\prime \prime}+B R e A 1 A 2 G F^{\prime} 2-F G^{\prime}=2 R A 2 G-F^{\prime \prime},
$$

and equation (6) yields

$$
\theta^{\prime \prime} \operatorname{Pr} \text { A2A3A1A4Re A1A2+F'"2Ec A22A1A31+RA24Re }
$$

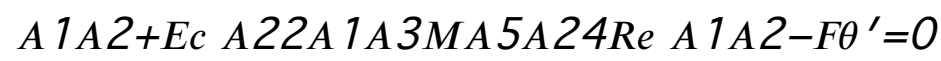

Equation (7) gives

$$
\psi^{\prime \prime}=\operatorname{Sc} \operatorname{Re} F \psi^{\prime},
$$


where $R(=k \mu)$ is the micropolar parameter, $B=j L 2$ is micropolar constant, $M=B 02 L 2 \sigma f \mu f$ is Hartmann Number, $\operatorname{Re}(=\rho V L \mu)$ is the injection Reynolds number, $\operatorname{Pr}(=\mu C p K)$ is the Prandtl number, $E c(=r 2 \mu 2 L 4(T 2-T 1) \rho 2 C p)$ is the Eckert number and $S c(=D \rho \mu)$ is the Schmidt number.
A $1=\rho n f \rho f ;$
$A 2=\mu n f \mu f$
$A 3=(\rho C p) n f(\rho C p) f$
$A 4=K n f K f$
$A 5=\sigma n f \sigma f$

Using dimensionless transformation equations (31-36) in the boundary conditions (12-21), we get

$$
\begin{aligned}
& \text { at } \eta=-1 ; F=1, F^{\prime}=0, G=-2 n F^{\prime \prime}, \theta=0, \psi=0, \\
& \text { at } \eta=1 ; F=-1, F^{\prime}=0, F=-2 n F^{\prime \prime}, \theta=1, \psi=1 .
\end{aligned}
$$

The shear stress and couple stress on the plate surfaces can be written as

$$
\begin{array}{r}
\tau w=(\mu n f+k) \partial V r \partial z+k v z= \pm 1, \\
m w=-\gamma n f \partial v \partial z z= \pm 1
\end{array}
$$

The rate of heat transfer and the rate of mass transfer from the plates are defined as

$$
\begin{gathered}
q w=-k \partial v T \partial z z= \pm 1 \\
j w=-D \partial C \partial z z= \pm 1
\end{gathered}
$$

The quantities important from the engineering application point of view are skin coefficient friction $\left(c_{f}\right)$, non-dimensional couple stress $\left(C_{n}\right)$, Nusselt Number $(\mathrm{Nu})$ and Sherwood Number (Sh) which are derived from (44)-(47) using (31)-(36) for the lower plate,

$$
\begin{gathered}
\text { Re } c f=-A 2+1-n R 1-\phi+\phi A 1 F^{\prime \prime}(-1) \\
C n=-A 2+R / 22 B \operatorname{Re} G^{\prime}(-1) \\
N u=\theta^{\prime}(-1) \\
S h=\psi^{\prime}(-1)
\end{gathered}
$$




\section{Method of solution}

The nonlinear differential equations (37-40) which represent the velocity distribution, microrotation, temperature distribution and concentration respectively, along with the respective boundary conditions (42-43) were solved numerically using the Runge-Kutta fourth order method along with shooting technique. In order to solve these nonlinear higher order equations firstly, they were reduced to a set of first order differential equations. Then, the suitable guesses were passed to the function as the initial solution. The computations were done for a mesh size of 10000-50000 and the tolerance limit was set to .001.

\section{Results and Discussion}

To study the fluid flow behavior of an incompressible viscous flow of micropolar nanofluid between two coaxial porous plates under the effect of uniform magnetic field, dimensionless velocity components, micro-rotation, temperature and concentration distributions are analyzed for different emerging physical parameters such as $R, M, R e, n, E c, \operatorname{Pr}$ and $S c$. The nanoparticles Copper Oxide $(\mathrm{CuO})$ and Alumina $\left(\mathrm{Al}_{2} \mathrm{O}_{3}\right)$ are mixed with base fluid water to prepare the nanofluids i.e. $\mathrm{CuO}$-water and $\mathrm{Al}_{2} \mathrm{O}_{3}$-water to investigate the effects of magnetic field, microrotation parameter and nanoparticle volumetric fraction in this model.

Figures 2-4 show the result of $\mathrm{CuO}$ water with microelement nanofluids for the influence of Reynolds number on axial velocity and radial velocity, micro-rotation, temperature distribution and concentrate distribution when other physical parameters are fixed as micro-rotation parameter $(\mathrm{R})=5$, magnetic parameter $(\mathrm{M})=2, \mathrm{n}=0.5$ (strong concentration of microelements), Prandtl number $(\mathrm{Pr})=0.5$ and the Schmidt number $(\mathrm{Sc})=1$ and Eckart number $(\mathrm{Ec})=0.1$. It is observed from Fig 2 that the axial velocity profiles are not symmetric whereas the radial velocity profiles are symmetric.

The value of the axial velocity at a fixed point increases with increasing the Reynolds number. But the value of radial velocity increases with increasing the Reynolds number near the stagnation point $(\eta=0)$ but near the plate it decreases with increasing the Reynolds number. Physically this follows from the fact that by increasing the strength of the blowing velocity which refers to increasing the Reynolds number, causes to increase the axial velocity for any point except stagnation point. Another side, by increasing the blowing velocity at the plates, the radial velocity increases near the stagnation point. But near the plate due to viscous force (no slip condition), it decreases. The behavior of the motion for the $\mathrm{Al}_{2} \mathrm{O}_{3}$ water remains same with various values of Reynolds number.

Figure 3 (a)-(b) shows that in the case of $\mathrm{CuO}$-water micropolar nanofluid, the values of micro-rotation at fixed point of $\eta$ increase with increasing the value of Re when other parameters are fixed (as $\mathrm{R}=5, \mathrm{M}=2, \operatorname{Pr}=0.5, \mathrm{Sc}=1$ and $\mathrm{Ec}=0.1$.) for either $\mathrm{n}=0$ and $\mathrm{n}=0.5$. It is interesting to note that the value of micro-rotation of microelements for $\mathrm{CuO}$ water nanofluids are more in the case of strong concentration of microelements than the case of weak concentration of microelements. But in the case weak concentration of microelements i.e. $n=0.5$, the antisymmetric part of the stress tensor vanishes near the plates and the negative rotation of the 
microelements are diffused away from the plates. So that the micro-rotation of microelements becomes weak and its value is positive in the region between the lower plate and stagnation point and becomes negative in the region between stagnation point flow and upper plate. The contrary results are observed in the case strong concentration of microelements. The temperature and concentration of the fluid decrease with increasing Re i.e. blowing parameter in the region between the lower plate and stagnation point. But opposite results are noticed in region of stagnation point and upper plate (shown in Fig 4).

Figure 5-7 depict the profiles of velocities, micro-rotation, temperature and concentration distribution for $\mathrm{CuO}$-water micropolar nanofluid with various values of micro-rotation parameter $\mathrm{R}$ when $\mathrm{Re}=5, \mathrm{M}=2, \mathrm{n}=0.5$ (strong concentration of microelements), $\mathrm{Pr}=0.5, \mathrm{Sc}=1$ and $\mathrm{Ec}=0.1$. It is seen that the axial velocity at a point decreases with increasing micro-rotation parameter when other parameters are fixed but the radial velocity decreases near the stagnation point for increasing the micro-rotation parameter and it increases near the plates (see Fig 5 (a)-(b)). It is found from the Fig 6(a)-(b) that the micro-rotation of microelements of nanofluid at point decreases with increasing micro-rotation parameter in the case of weak concentration of microelements. On the other hand, micro-rotation at the point increases with increasing $\mathrm{R}$ in the case strong concentration of microelements. Since micro-rotation at the plate is non-zero due to weak concentration of microelements, micro-rotation is diffused away from the plates with having negative direction of rotation and opposes the micro-rotation of the microelements of nanofluid due to anti-symmetric part of stress tensor. So by increasing the value of microrotation parameter, micro-rotation of the microelements decreases. But the micro-rotation becomes zero at the plates due to strong concentration of microelements, the micro-rotation is not opposed by the diffused microelements from the plates. Therefore, micro-rotation increases with increasing the value of micro-rotation parameter. From Fig 7(a) shows the temperature at point near the lower plate decreases with increasing the micro-rotation and near the upper plate increases with increasing rotation parameter as it is considered temperature of lower plate is higher than the upper plate. As expected from Fig 7(b), that concentration of $\mathrm{CuO}$-water nanofluids at point decreases with increasing the micro-rotation.

Figures 8-10 demonstrate the effect of magnetic parameter on the velocity, micro-rotation, temperature and concentration distribution for $\mathrm{CuO}$ water micropolar nanofluid when $R e=5, R$ $=5, \mathrm{n}=0.5$ (strong concentration of microelements), $P r=0.5, S c=1$ and $E c=0.1$. If the strength of the transverse magnetic field is increased, the Lorentz force acts as more retarding force on the velocity field. So that axial and radial velocity at a point far from the plates decreases with increasing the magnetic parameter (see Fig 8 (a)-(b)). It is interesting to observe from fig 9(a)(b) that micro-rotation at point increases with increase in the value of magnetic field when $\mathrm{n}=0.5$ but the micro-rotation decreases with increasing the value of magnetic field when $n=0$. A physical interpretation for this contrast result can be analyzed as micro-rotation at the plates is considered zero for $\mathrm{n}=0$ and applied magnetic field decelerates the angular rotation which results the value of micro-rotation decreases with increasing the magnetic field. In the case $n=0.5$, due to weak concentration of the microelements, the angular rotation at the plates dominates the retarding force generated by magnetic field. So that micro-rotation increases with increasing the magnetic field. It is noticed from Fig 10 (a) that by applying magnetic field, joule heating is increased. Therefore, the temperature at point increases with increasing the magnetic field. The retarding forced caused by applying magnetic field, results that the concentration at point 
decreases with increasing the magnetic field. Fig 11 shows that the concentration of $\mathrm{CuO}$ water micropolar nanofluid at point decreases with increasing the Schmidt number.

Table 2: $\mathrm{CuO}$ - water : Skin friction coefficient $\left(c_{f}\right)$, couple stress $\left(C_{n}\right)$, the local heat transfer coefficient $(\mathrm{Nu})$, and rate of mass transfer $(\mathrm{Sh})$ when $\operatorname{Re}=5, n=0.5, E c=0.1, S c=1, \operatorname{Pr}=0.5$

\begin{tabular}{|c|c|c|c|c|}
\hline $\boldsymbol{C u} \boldsymbol{O}-$ water & $\boldsymbol{c}_{\boldsymbol{f}}$ & $\boldsymbol{C}_{\boldsymbol{n}}$ & $\boldsymbol{N u}$ & $\boldsymbol{S} \boldsymbol{h}$ \\
\hline$\varphi=0.2, \mathrm{R}=2, \mathrm{M}=0$ & 3.266 & 2.944 & 0.307 & 0.044702439 \\
$\varphi=0.2, \mathrm{R}=2, \mathrm{M}=5$ & 3.455 & 3.096 & 0.319 & 0.045314684 \\
$\varphi=0.2, \mathrm{R}=2, \mathrm{M}=10$ & 3.639 & 3.244 & 0.331 & 0.045890802 \\
$\varphi=0.2, \mathrm{R}=2, \mathrm{M}=20$ & 3.988 & 3.529 & 0.355 & 0.046949971 \\
\hline $\mathrm{M}=5, \mathrm{R}=2, \varphi=0$ & 9.452 & 12.949 & 0.237 & 0.045636266 \\
$\mathrm{M}=5, \mathrm{R}=2, \varphi=0.1$ & 6.411 & 6.930 & 0.266 & 0.04523978 \\
$\mathrm{M}=5, \mathrm{R}=2, \varphi=0.2$ & 5.168 & 4.647 & 0.312 & 0.044951988 \\
\hline$\varphi=0.2, \mathrm{M}=5, \mathrm{R}=0$ & 2.047 & 0.440 & 0.295 & 0.043794805 \\
$\varphi=0.2, \mathrm{M}=5, \mathrm{R}=2$ & 3.455 & 3.096 & 0.319 & 0.045314684 \\
$\varphi=0.2, \mathrm{M}=5, \mathrm{R}=4$ & 4.751 & 6.423 & 0.341 & 0.045489007 \\
$\varphi=0.2, \mathrm{M}=5, \mathrm{R}=8$ & 7.200 & 13.720 & 0.385 & 0.045490828 \\
\hline
\end{tabular}

Table 2 illustrates the skin friction coefficient $\left(c_{f}\right)$, couple stress $\left(C_{n}\right)$, the local heat transfer coefficient $(\mathrm{Nu})$, and rate of mass transfer $(\mathrm{Sh})$ at lower disc for $\mathrm{CuO}-$ water micropolar nanofluid when $\operatorname{Re}=5, E c=0.1, S c=1, P r=0.5$ and Table 3 shows the same for $\mathrm{Al}_{2} \mathrm{O}_{3}-$ water micropolar nanofluid, when $\operatorname{Re}=5, E c=0.1, S c=1, \operatorname{Pr}=0.5$. It is found from the both Table 2 and 3 that the skin friction coefficient at the lower plate increase with increasing magnetic field for both $\mathrm{CuO}$ - water and $\mathrm{Al}_{2} \mathrm{O}_{3}-$ water. An interesting result is observed in this analysis that the skin friction coefficient at the lower plate decreases with increases the volume fraction of nanoparticles for both the $\mathrm{CuO}$-water and $\mathrm{Al}_{2} \mathrm{O}_{3}-$ water nanofliuds. Again its value increases with increasing the micro-rotation parameter. The couple stress increases as the both magnetic parameter and micro-rotation parameter increase. When the volume fraction of nanoparticles for both the $\mathrm{CuO}-$ water and $\mathrm{Al}_{2} \mathrm{O}_{3}-$ water nanofliuds increase, the couple stress decreases. It is also observed that the couple stress decreases with increase the volume fraction of nanoparticles. A novel result is found from this analysis that the rate of heat transfer at the lower plate increases with increasing the either magnetic parameter or the volume fraction of nanoparticles or micro-rotation parameter. the volume fraction of nanoparticles. The joule heating which increases with increasing magnetic parameter, causes to increase rate of heat transfer at the plate. On the other hand to increase the micro-rotation parameter, more heat will be generated at the plate due to the rotation of microelements of the nanoparticle. So that rate of heat transfer will increase to increase the micro-rotation parameter. The rate of mass transfer at the lower plate increases with increasing both magnetic parameter and micro-rotation parameter. But it increases with increasing the value of the volume fraction of nanoparticles. This analysis also 
shows that $\mathrm{CuO}$-water has higher skin friction and better rate of heat transfer than the $\mathrm{Al}_{2} \mathrm{O}_{3}$ -water nanofliuds.

Table 3: $\mathrm{Al}_{2} \mathrm{O}_{3}-$ water: skin friction coefficient $\left(c_{f}\right)$, couple stress $\left(C_{n}\right)$, the local heat transfer coefficient $(\mathrm{Nu})$, and rate of mass transfer $(\mathrm{Sh})$ when $\operatorname{Re}=5, n=0.5, E c=0.1, S c=1, \operatorname{Pr}=0.5$

\begin{tabular}{|c|c|c|c|c|}
\hline Al $_{2} \mathrm{O}_{3}-$ water & $c_{f}$ & $C_{n}$ & $N u$ & $S h$ \\
\hline$\varphi=0.2, \mathrm{R}=2, \mathrm{M}=0$ & 4.424 & 4.708 & 0.3449 & 0.04507599 \\
$\varphi=0.2, \mathrm{R}=2, \mathrm{M}=5$ & 4.692 & 4.952 & 0.3653 & 0.045702691 \\
$\varphi=0.2, \mathrm{R}=2, \mathrm{M}=10$ & 4.950 & 5.188 & 0.3858 & 0.046291512 \\
$\varphi=0.2, \mathrm{R}=2, \mathrm{M}=20$ & 5.440 & 5.640 & 0.4270 & 0.047370169 \\
\hline $\mathrm{M}=5, \mathrm{R}=2, \varphi=0$ & 9.452 & 12.950 & 0.2373 & 0.045636266 \\
$\mathrm{M}=5, \mathrm{R}=2, \varphi=0.1$ & 7.788 & 9.277 & 0.2916 & 0.045448459 \\
$\mathrm{M}=5, \mathrm{R}=2, \varphi=0.2$ & 7.007 & 7.431 & 0.3530 & 0.045331494 \\
\hline$\varphi=0.2, \mathrm{M}=5, \mathrm{R}=0$ & 2.829 & 0.824 & 0.3254 & 0.044718634 \\
$\varphi=0.2, \mathrm{M}=5, \mathrm{R}=2$ & 4.692 & 4.952 & 0.3653 & 0.045702691 \\
$\varphi=0.2, \mathrm{M}=5, \mathrm{R}=4$ & 6.373 & 9.711 & 0.4039 & 0.045794124 \\
$\varphi=0.2, \mathrm{M}=5, \mathrm{R}=8$ & 9.564 & 19.709 & 0.4802 & 0.045589461 \\
\hline
\end{tabular}

\section{Conclusion}

In this article, a numerical investigation of MHD flow, heat and mass transfer of an electrically conducting micropolar nanofluid between two coaxial porous plates with uniform blowing has been examined. The following important conclusions are made from our analysis.

- The skin friction coefficient at the lower plate increases with increasing the magnetic field for both $\mathrm{CuO}$ - water and $\mathrm{Al}_{2} \mathrm{O}_{3}-$ water micropolar nanofluid. But the skin friction coefficient at the lower plate decreases with increases the volume fraction of nanoparticles in the case of both fluids.

- The couple stress at lower the plate increases by increasing both the magnetic parameter and micro-rotation parameter but it decreases with increasing the volume fraction in case of both fluids ( $\mathrm{CuO}-$ water and $\mathrm{Al}_{2} \mathrm{O}_{3}-$ water micropolar nanofluids).

- The rate of heat transfer at the lower plate increases with increasing the either magnetic parameter or the volume fraction of nanoparticles or micro-rotation parameter or the volume fraction of nanoparticles.

- The axial velocity is not symmetric but the radial velocity profiles are symmetric. By increasing the blowing velocity, the radial velocity increases near the stagnation point but decreases near the plates. The radial velocity near the stagnation point decreases with increasing the magnetic field and micro-rotation parameter. It is interesting that axial 
velocity becomes zero at stagnation point and it increases with increasing the blowing velocity far from plate but not near the stagnation point. It decreases with increasing the micro-rotation parameter and magnetic field in the same region.

- The temperature and concentration of the fluid decrease with increasing the blowing parameter (i.e. Reynolds number) in the region between the lower plate and stagnation point and its behavior is reverse in region of stagnation point and upper plate. The temperature at point increases with increasing the magnetic field as well as micro-rotation parameter. But the concentration at point increases by increasing the magnetic parameter and micro-rotation parameter in the region between lower plate and stagnation point flow but contrary results are found in the region between stagnation point and the upper plate.

Acknowledgements: The second and third authors acknowledge the facilities and support provided by the National Institute of Science and Technology, Berhampur. The second author (M. R.) would like to acknowledge the use of the facilities and technical assistance of the Center for Theoretical Studies at Indian Institute of Technology, Kharagpur. The authors also thank the referees of the paper for their critical comments which have led to an improved presentation of the paper.

\section{References}

[1] S.U.S. Choi, J.A. Eastman, Enhancing thermal conductivity of fluids with nanoparticle, in:D.A. Siginer, H.P. Wang (Eds.), Developments and Applications of Non-Newtonian Flows, ASME FED, vol. 231 / MD-vol. 66, (1995), 99105.

[2] J. A. Eastmana, S. U. S. Choi, S. Li, L. J. Thompson and S. Lee, Enhanced Thermal Conductivity through the Development of Nanofluids, MRS Proceedings, 457, (1996),

[3] H. Masuda, A. Ebata, K. Teramae, N. Hishinuma, Alteration of thermal conductivity and viscosity of liquid by dispersing ultra-fine particles (Dispersion of $\mathrm{Al}_{2} \mathrm{O}_{3}, \mathrm{SiO}_{2}$ and $\mathrm{TiO}_{2}$ ultra-fine particles), NetsuBussei(Japan), 7, (1993) 227-233.

[4] B.C. Pak, Y.I. Cho, Hydrodynamic and heat transfer study of dispersed fluids with submicron metallic oxide particles, Experimental Heat Transfer, 11 (1998) 151170

[5] R. K.Tiwari, M. K. Das, Heat transfer augmentation in a two-sided lid-driven differentially heated square cavity utilizing nanofluids, Int. J Heat Mass Transf, 50, (2007), 2002-2018.

[6] J. Buongiorno, Convective Transport in Nanofluids, ASME Journal of Heat Transfer, 128, (2006) 240250.

[7] A. C. Eringen, Simple microfluids, International Journal of Engineering Science, 2(2), (1964) 205217.

[8] A. C. Eringen, Theory of micropolar fluids, Journal of Applied Mathematics and Mechanics, 16(1), (1996) 118.

[9] O. Anwar Beg, M.M. Rashidi, M. Akbari, A. Hosseini, Comparative numerical study of single-phase and twophase models for bio-nanofluid transport phenomena, Journal of Mechanics in Medicine and Biology 14 (1) (2014) Article number 14500110.

[10] M.M. Rashidi, A. Hosseini, I. Pop, S. Kumar, N. Freidoonimehr, Comparative numerical study of single and two-phase models of nanofluid heat transfer in wavy channel, Applied Mathematics and Mechanics (English Edition) 35 (7) (2014) 831-848.

[11] M. H. Abolbashari, N. Freidoonimehr, F. Nazari, M.M. Rashidi, Entropy Analysis for an unsteady MHD flow past a stretching permeable surface in nano-fluid, Powder Technology 267 (2014) 256-267. 
[12] N. Freidoonimehr, M.M. Rashidi, S. Mahmud, Unsteady MHD free convective flow past a permeable stretching vertical surface in a nano-fluid, International Journal of Thermal Sciences 87 (2015) 136-145.

[13] M.M. Rashidi, E. Momoniat, M. Ferdows, A. Basiriparsa, Lie group solution for free convective flow of a nanofluid past a chemically reacting horizontal plate in a porous media, Mathematical Problems in Engineering (2014) 239082.

[14] H. Zargartalebi, M. Ghalambaz, A. Noghrehabadi, A. ChamkhaStagnation-point heat transfer of nanofluids toward stretching sheets with variable thermo-physical properties, Advanced Powder Technology, 26, (3), (2015), 819-829.

[15] Saeed Dinarvand, Reza Hosseini, Milad Abulhasansari, Ioan Pop, Buongiorno's model for double-diffusive mixed convective stagnation-point flow of a nanofluid considering diffusiophoresis effect of binary base fluid, Advanced Powder Technology, 26, (5), (2015), 1423-1434.

[16] A. Malvandia, S.A. Moshizib, D.D. Ganjic, Effect of magnetic fields on heat convection inside a concentric annulus filled with A12O3-water nanofluid, Advanced Powder Technology, 25, 6, (2014), 1817-1824.

[17] S. Kumar, J. J. Yao, A. Kumar, A fractional model to describing the Brownian motion of particles and its analytical solution, Advances in Mechanical Engineering, 7(12), (2015) 1-11.

[18] S. Kumar, X. Yin, D. Kumar, A modified homotopy analysis method for solution of fractional wave equations, Advances in Mechanical Engineering, 7(12), (2015) 1-8.

[19] S. Kumar, A. Kumar, Dumitru Baleneu, Two analytical method for time -fractional nonlinear coupled Boussinesq-Burger equations arises in propagation of shallow water waves, Nonlinear Dynamics, (2015) 1-17, (2016).

[20] S. Kumar, D. Kumar, Jagdev Singh, Fractional modelling arising in unidirectional propagation of long waves in dispersive media, Advances in Nonlinear Analysis, (DOI: 10.1515/anona-2013-0033), 2016

[21] F. Garoosi, L. Jahanshaloo, M.M. Rashidi, A. Badakhsh, M.A. Ali, Numerical Simulation of Natural Convection of the Nanofluid in Heat Exchangers using a Buongiorno Model, Applied Mathematics and Computation 254 (2015) 183203.

[22] F. Garoosi, B. Rohani, M.M. Rashidi, Two-Phase Mixture Modeling of Mixed Convection of Nanofluids in a Square Cavity with Internal and External Heating, Powder Technology 275 (2015) 304321.

[23] F. Garoosi, G. Bagheri, M.M. Rashidi, Two phase simulation of natural convection and mixed convection of the nanofluid in a square cavity, Powder Technology 275 (2015) 239256.

[24] G. Lukaszewicz, Micropolar fluids: Theory and applications, Brikhauser Basel, 1999.

[25] S.T. Hussain, S. Nadeem and R. U. Haq, Model-based analysis of micropolar nanofluid flowover a stretching surface, Eur. Phys. J. Plus, 129, (2014) 161.

[26] A. Rehman, S. Nadeem, Mixed convection heat transfer in Micropolar nanofluid over a vertical slender cylinder, Chin Phys Lett, 29, (2012) 124701.

[27] S. Nadeem, A. Rehman, K. Vajravelu, J. Lee, C. Lee, Axisymmetric stagnation flow of a micropolar nanofluid in a moving cylinder, Mathematical Problems in Engineering, 2012, (2012), ID 378259, 18.

[28] A. Zaraki, M. Ghalambazb, A. Chamkha, M. Ghalambazb, D. D. Rossi , Theoretical analysis of natural convection boundary layer heat and mass transfer of nanofluids: Effects of size, shape and type of nanoparticles, type of base fluid and working temperature, Advanced Powder Technology 26, (2015) 935-946.

[29] H. Zargartalebi, M. Ghalambaz, A. Noghrehabadi, A. Chamkha, Stagnation-point heat transfer of nanofluids toward stretching sheets with variable thermo-physical properties, Advanced Powder Technology 26, (2015) 819-829.

[30] M. Ghalambaz, E. Izadpanahi, A. Noghrehabadi, A. Chamkha, Study of the boundary layer heat transfer of nanofluids over a stretching sheet: Passive control of nanoparticles at the surface, Can. J. Phys. 93, (2015) 725733.

[31] A. Noghrehabadadi; M. Ghalambaz; A. Ghanbarzadeh, Heat Transfer of Magnetohydrodynamic Viscous Nanofluids over an Isothermal Stretching Sheet, Journal of thermophysics and heat transfer 26 (4), (2012) 686689.

[32] A. Noghrehabadi, M. Ghalambaz and A. Ghanbarzadeh, Effects of variable viscosity and thermal conductivity on natural-convection of nanofluids past a vertical plate in porous media, Journal of Mechanics 30 (03), (2014) 265-275. 
[33] A. S. Berman. Laminar Flow in Channels with Porous Walls, J. Appl.Phys., 24, 9, (1953), 1232-1235.

[34] J. R. Sellars, Laminar flow in a channel with porous walls at high suction Reynolds number, J. Appl.Phys., 26, (1955), 489-490.

[35] S. W. Yuan, Further Investigation of Laminar Flow in Channels with Porous Walls, J. Appl.Phys., 27(3), (1956), 267-269.

[36] A.F. Elkouh, Laminar ow between porous discs, J. Eng. Mech. Div. ASCE. 93 (1967), 5375.

[37] C. L. Narayana, N. Rudraiah, On the steady flow between a rotating and a stationary disk with a uniform suction at the stationary disk, Zeitschrift fr angewandte Mathematik und Physik ZAMP, 23(1), (1972) 96-104.

[38] N. Rudraiah, B. C. Chandrasekhara, Flow of a conducting fluid between porous disks for large suction Reynolds number, Phys Soc. Japan 27, (1969) 1041-1045.

[39] H. Rasmussen, Steady viscous flow between two porous disks, Z. Angewn. Math. Phys. 21, (1970) 187-195.

[40] T.W. Chapman, G. L. Bauer, Stagnation-point viscous flow of an incompressible fluid between porous plates with uniform blowing, Appl. Sci. Res. 31, (1975) 223.

[41] A. R. Elcrat, On the radial flow of a viscous fluid between two porous disks, Arch. Rat. Mech. Anal. 61, (1976) 91-96.

[42] Y. N. Gaur, R. C. Chaudhary, Heat transfer for laminar flow through parallel porous disks of different permeability Proceedings of the Indian Academy of Sciences - Mathematical Sciences, 87(9), (1978) 209-217.

[43] N. M. Bujurke, P.K. Achar, A semi-analytic approach to the viscous flow between a rotating and a stationary disk,Fluid Dynamics Research, 10(2), (1992) 91-99.

[44] N. M. Bujurke, N. P Pai P. K. Achar, Semi-analytic approach to stagnation-point flow between porous plates with mass transfer, Indian J. Pure and Applied Mathematics, 26(4) (1995), 373-389.

[45] R.S. Agarwal, and C. Dhanapal, Stagnation Point Micropolar Fluid Flow between Porous Discs with Uniform Blowing. Int. J. Engineering Science, 26, (1988) 293-300.

[46] G. S. Guram, M. Anwar, Steady flow of a micropolar fluid due to a rotating disk. Journal of Engineering Mathematics, 13(3), (1979) 223234.

[47] G. S. Guram, M. Anwar, Micropolar flow due to a rotating disk with suction and injection. Zeitschrift fur Angewandte Mathematik und Mechanik, 61(11), (1981) 589605.

[48] H. S. Takhar, R. Bhargava, R. S. Agrawal, A. V. S. Balaji, Finite element solution of micropolar fluid flow and heat transfer between two porous disks, Int. Journal of Engineering Science, 38(17), (2000) 19071922.

[49] X. L. Wang, and K. Q. Zhu, Numerical analysis of journal bearings lubricated with micropolar fluids including thermal and cavitating effects. Tribology International, 39(3), (2006) 227237.

[50] M. Anwar-Kamal, M. Ashraf, and K. S. Syed, Numerical solution of steady viscous flow of a micropolar fluid driven by injection between two porous disks, Applied Mathematics and Computation, 179(1), (2006) 110.

[51] M. Anwar-Kamal, M. Ashraf, and K. S. Syed, Numerical simulation of flow of a micropolar fluid between a porous disk and a non-porous disk. Applied Mathematical Modelling, 33(4), (2009) 19331943.

[52] M. Ashraf, A. R. Wehgal, MHD flow and heat transfer of micropolar fluid between two porous disks, Applied Mathematics and Mechanics, 33(1),(2012) 51-64.

[53] R. Nazar, N. Amin, I. Pop, Mixed convection boundary-layer flow from a horizontal circular cylinder in micropolar fluids: case of constant wall temperature, Int. J. Numer. Methods Heat Fluid Flow 13 (1), (2003) 86-109.

[54] S. M. Aminossadati, B. Ghasemi, Natural convection cooling of a localised heat source at the bottom of ananofluid-filled enclosure, European J Mechanics-B/Fluids., 28 (2009) 630-640.

[55] N. Anbuchezhian, K. Srinivasan, K. Chandrasekaran, R. Kanasamy, Thermoporesis and Brownian motion effects on boundary layer flow of nanofluid in presence of thermal stratification due to solar energy, Appl. Math. Mech. (Eng. Ed.) 33 (6) (2012) 765-780. 


\section{Caption of Figures}

Figure 2: (a) Variation of axial velocity with Re

Figure 2: (b) Variation of radial velocity with Re

Figure 3: (a)Variation of microrotation with $R e$ when $n=0.5$

Figure 3: (b)Variation of radial velocity with Re when $n=0.0$

Figure 4: (a)Variation of temperature with Re

Figure 4: (b)Variation of concentration with Re

Figure 5: (a) Effect of microrotation parameter on axial velocity

Figure 5: (b) Effect of microrotation parameter on radial velocity

Figure 6: (a)Variation of microrotation with $\mathrm{R}$ when $\mathrm{n}=0: 5$

Figures 6: (b)Variation of microrotation with $\mathrm{R}$ when $\mathrm{n}=0$

Figure 7: (a)Variation of temperature with microrotation parameter (R)

Figure 7: (b)Variation of concentration with microrotation parameter (R)

Figure 8: (a) Effect of magnetic field (M) on axial velocity

Figure 8: (b) Effect of magnetic field (M) on radial velocity

Figure 9: (a)Variation of microrotation with $\mathrm{M}$ at $\mathrm{n}=0.5$

Figure 9: (b)Variation of microrotation with $\mathrm{M}$ at $\mathrm{n}=0.0$

Figure 10: (a)Variation of temperature with $\mathrm{M}$

Figure 10: (b)Variation of concentration with $M$

Figure 11: Concentration Distribution for varying Sc, $n=0.5$ 

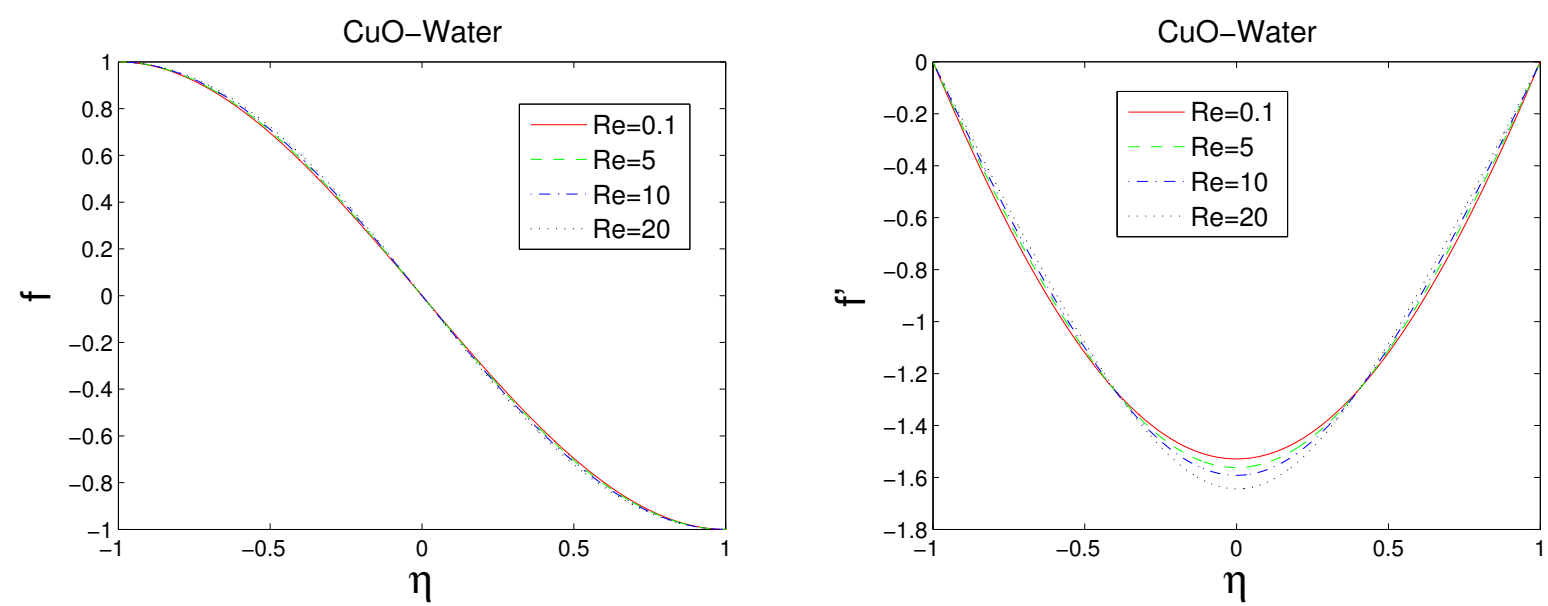

Figure 2: (a)Variation of axial velocity with Re (b)Variation of radial velocity with Re
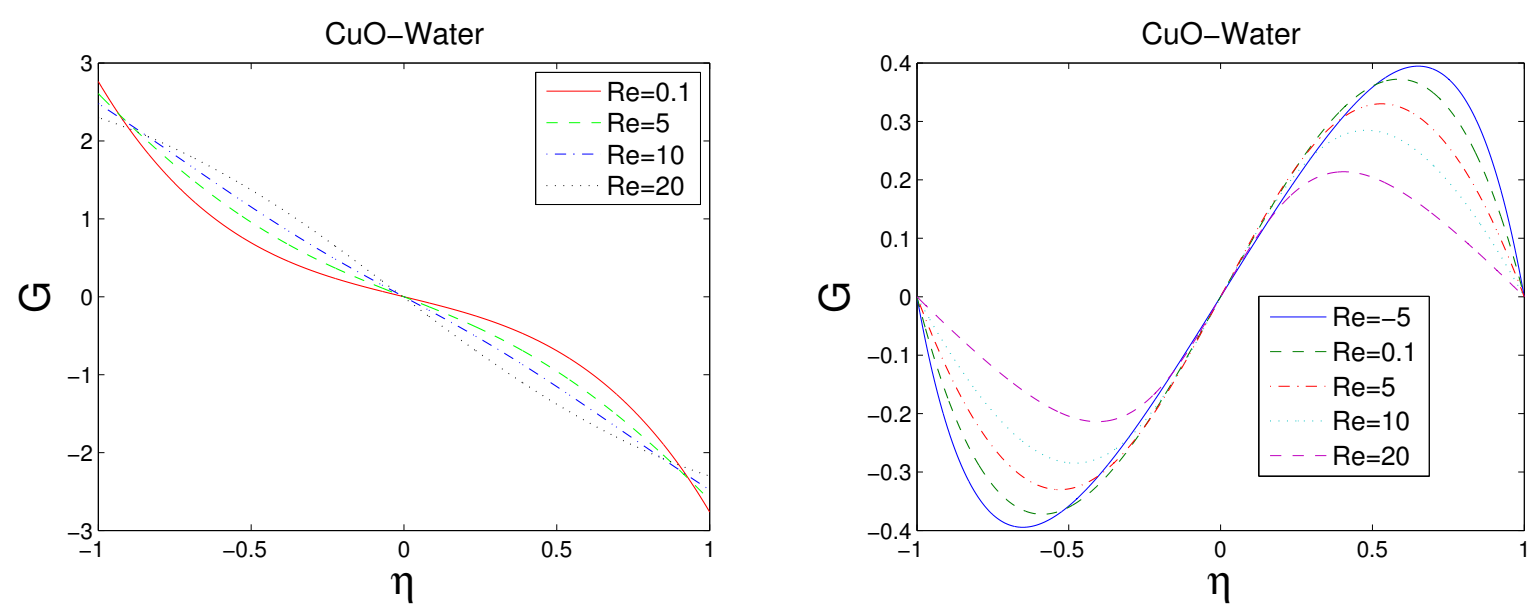

Figure 3: (a)Variation of microrotation with Re when $n=0.5$ (b)Variation of radial velocity with Re when $\mathrm{n}=0.0$ 

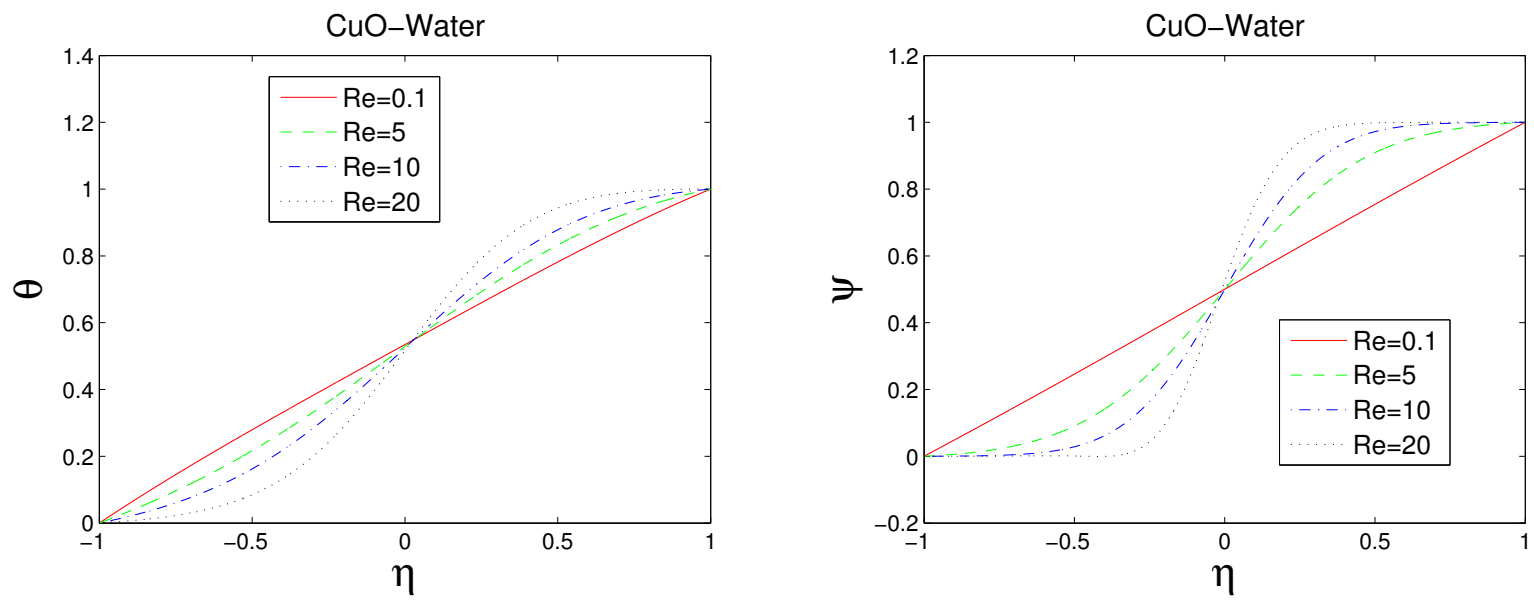

Figure 4: (a)Variation of temperature with Re (b)Variation of concentration with Re
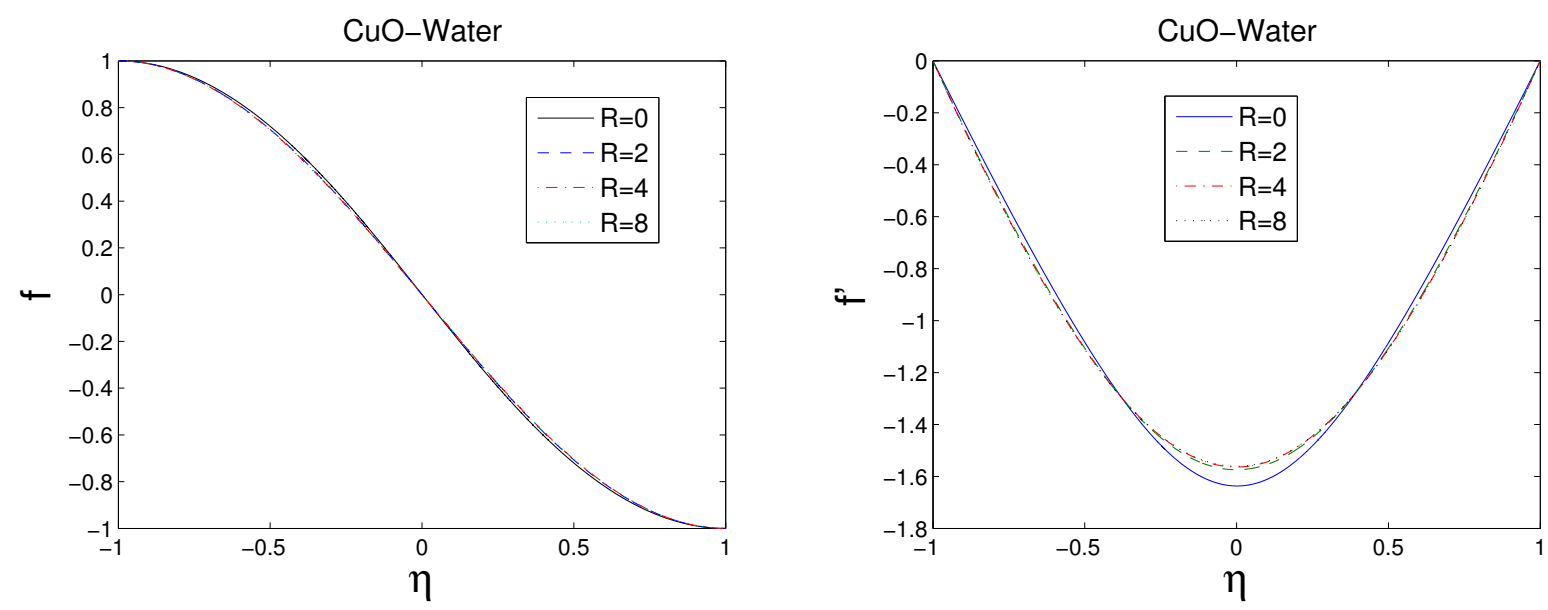

Figure 5: (a)Effect of microrotation parameter on axial velocity (b)Effect of microrotation parameter on radial velocity 

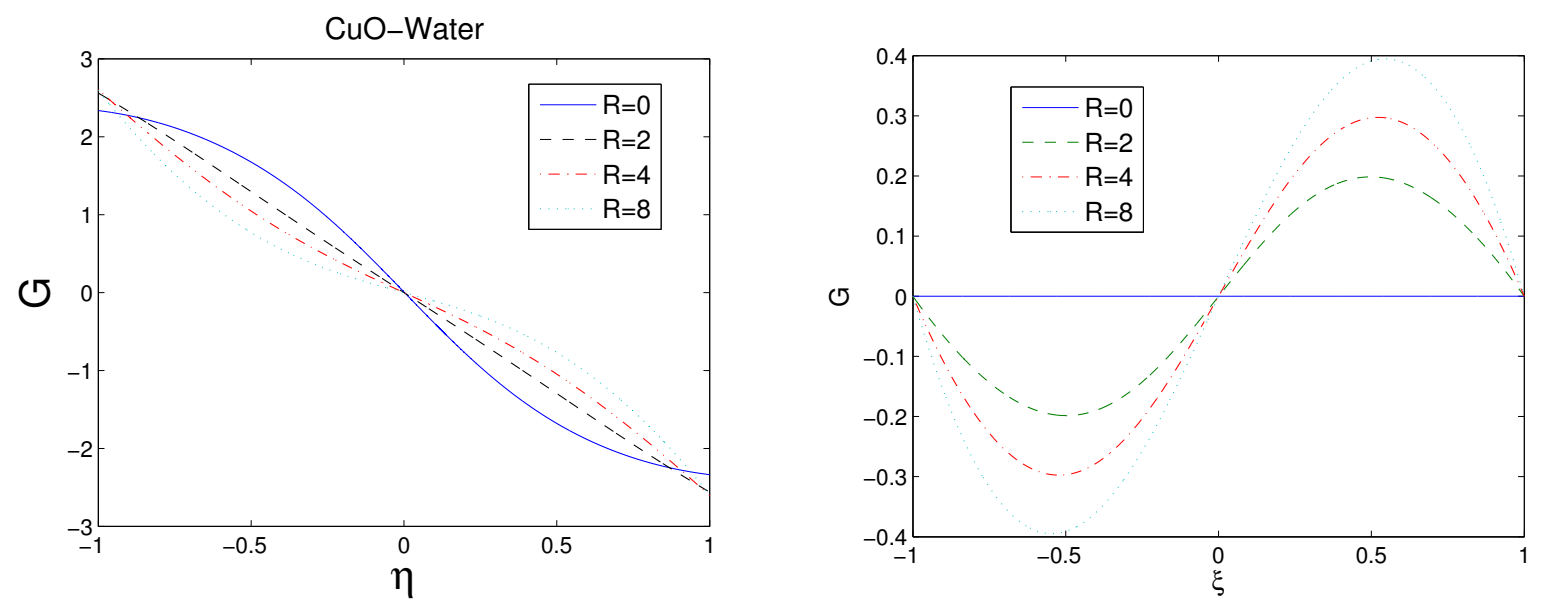

Figure 6: (a)Variation of microrotation with $\mathrm{R}$ when $n=0.5$ (b)Variation of microrotation with $\mathrm{R}$ when $n=0$
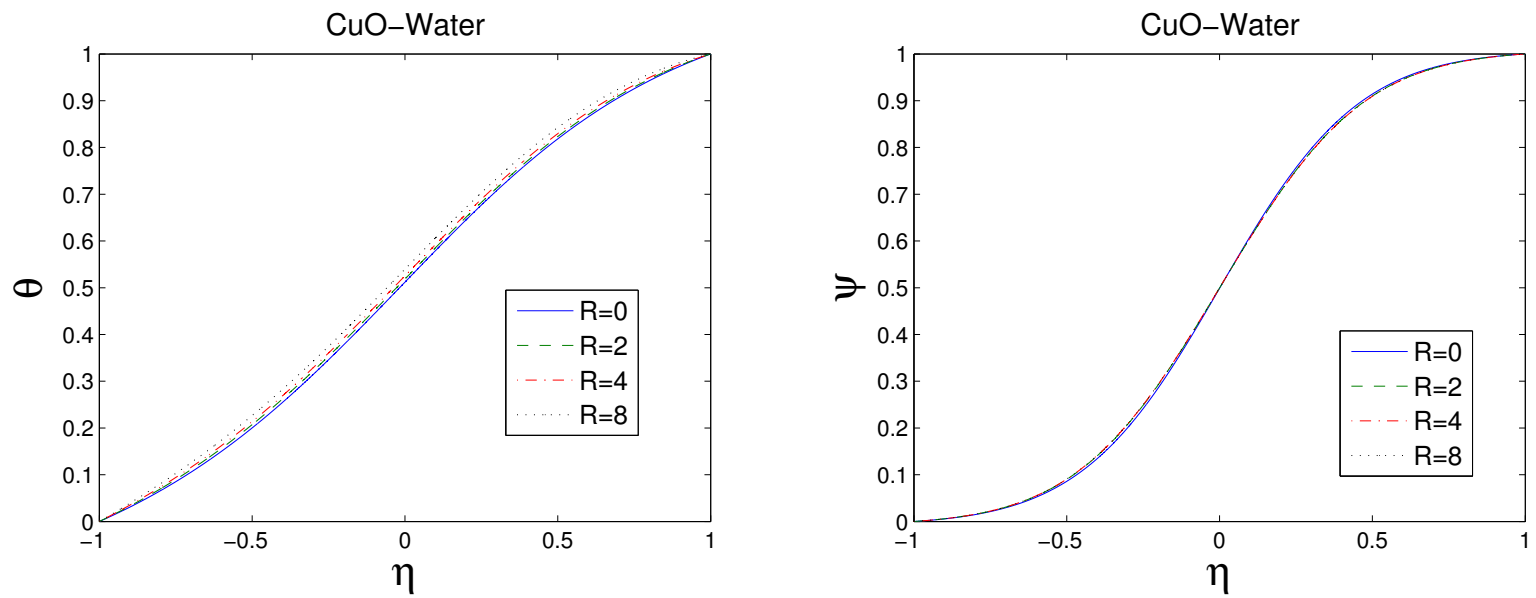

Figure 7: (a)Variation of temperature with microrotation parameter (R) (b)Variation of concentration with microrotation parameter $(\mathrm{R})$ 


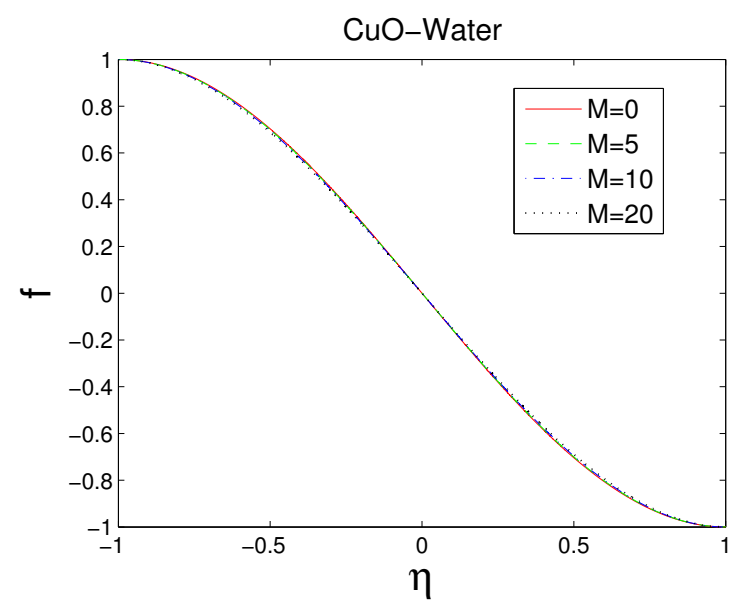

Figure 8: Effect of magnetic field (M) on axial velocity

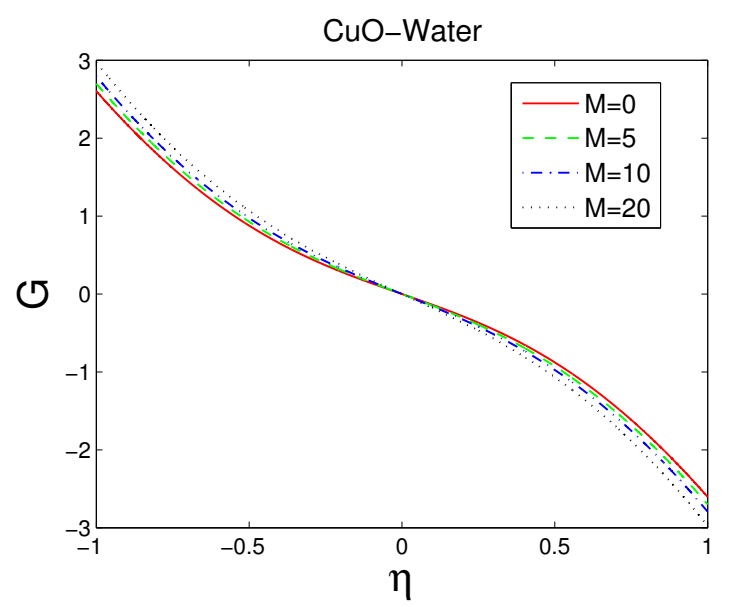

Figure 9: (a)Variation of microrotation with $\mathrm{M}$ at $\mathrm{n}=0.5$

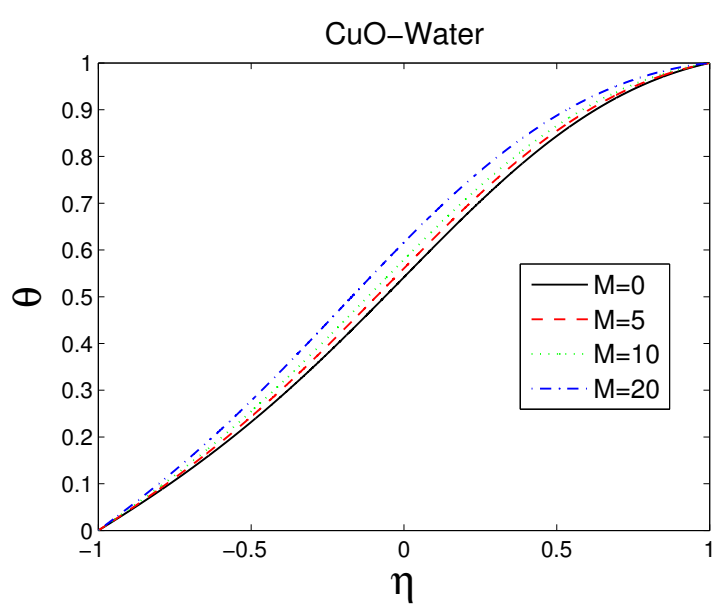

Figure 10: (a)Variation of temperature with M

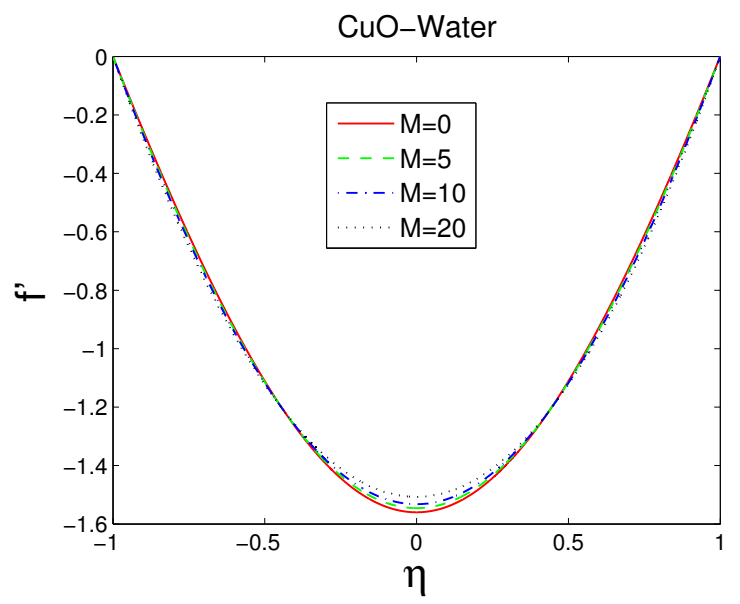

(b) Effect of magnetic field (M) on radial velocity

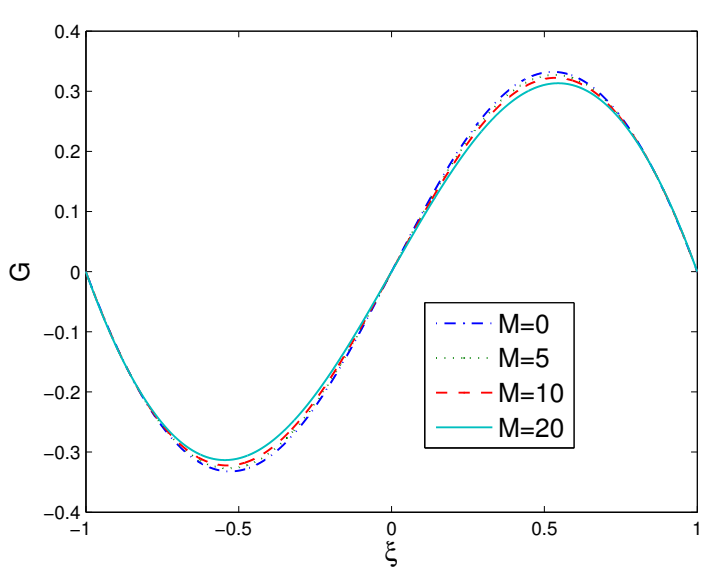

(b) Variation of microrotation with $\mathrm{M}$ at $\mathrm{n}=0.0$

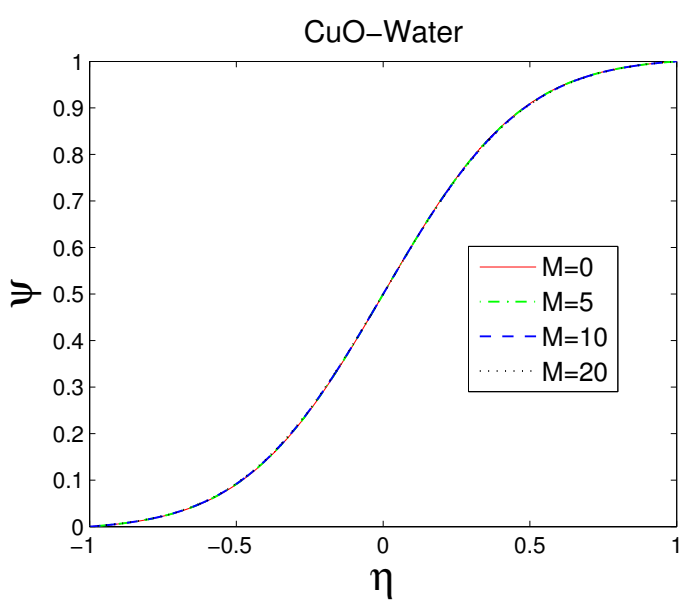

(b) Variation of concentration with M 


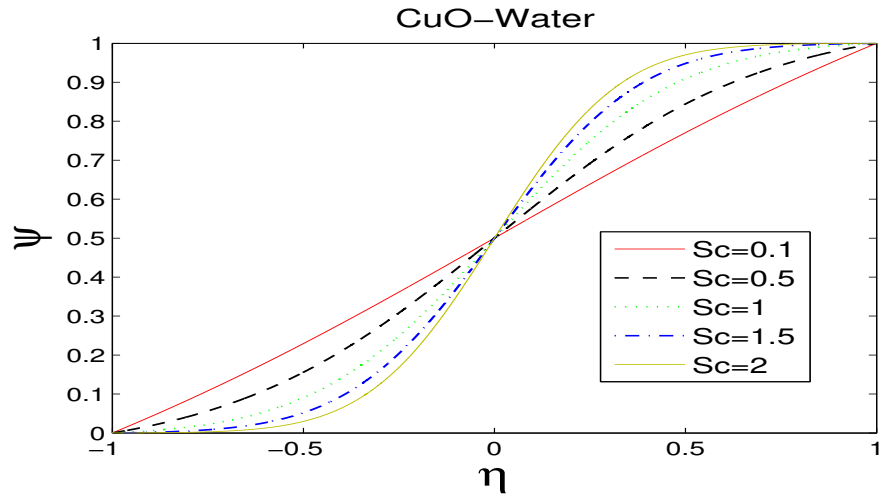

Figure 11: Concentration Distribution for varying Sc, $n=0.5$ 